Engineering and Design

Elsevier Editorial System(tm) for Fusion

Manuscript Draft

Manuscript Number: FUSENGDES-D-18-00693

Title: Pressure tests supporting the qualification of the ITER EC H\&CD upper launcher diamond window

Article Type: SI:SOFT-30

Keywords: ITER, Upper Launcher, Diamond, Window, Prototype

Corresponding Author: Dr. Sabine Schreck,

Corresponding Author's Institution: Karlsruhe Institute of Technology

First Author: Sabine Schreck

Order of Authors: Sabine Schreck; Gaetano Aiello; Natalia Casal; Violeta Gracia; Mark Henderson; Andreas Meier; Gabriella Saibene; Theo Scherer; Dirk Strauss; Paul Wouters

Abstract:

The Electron Cyclotron diamond window which is located inside the port cell serves, together with an isolation valve, as primary vacuum boundary between the ITER vacuum vessel, the transmission lines and the port cell atmosphere and it functions as confinement barrier. The window consists of an ultra-low loss Chemical Vapor Deposition (CVD) diamond disk brazed into a metallic housing and it has to guarantee the compliance with very stringent nuclear safety requirements and an adequate transmission capability for high power mm-waves (1.31 MW at $170 \mathrm{GHz}$ ). The design of the window unit is approaching its final phase including design validation analyses, the development of a dedicated qualification program and prototyping activities.

In preparation of the testing of complete window prototypes, pressure tests were performed on a mock-up formed by a diamond disk ( $D=80 \mathrm{~mm}, \mathrm{~d}$ $=1.11 \mathrm{~mm}$ ) brazed to two copper cuffs. The scope of the experiments was to show both the capability of the joining between the disk and the cuffs to keep the required vacuum tightness as well as the integrity of the disk when exposed to pressure loads. Based on the requirements defined for the pressure scenarios during normal operation and off-normal events, a test program was developed accounting for cyclic tests at low pressure differentials and overpressure tests up to 2 bar pressure difference over the disk to simulate severe accidental conditions.

This paper gives an outline of the ongoing development of the overall qualification program of the ITER torus window and reports specifically on the experimental set-up and the successful outcome of the pressure tests of the brazed diamond disk mock-up. The test program for the complete window prototype needs discussion and approval by F4E and ITER and will directly determine the final qualification program for the series diamond windows. 
Pressure tests supporting the qualification of the ITER EC H\&CD upper launcher diamond window

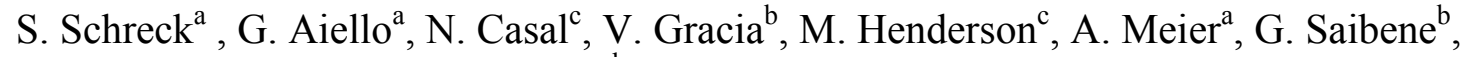
T. Scherer ${ }^{\mathrm{a}}$, D. Strauss ${ }^{\mathrm{a}}$, P. Wouters ${ }^{\mathrm{b}}$

${ }^{a}$ Karlsruhe Institute of Technology, Institute for Applied Materials, Association KIT-EURATOM,

P.O. Box 3640, D-76021 Karlsruhe, Germany

${ }^{b}$ F4E Joint Undertaking, Josep Pla 2, 08019 Barcelona, Spain

${ }^{c}$ ITER Organization, Route de Vinon-sur-Verdon, CS 90 046, 13067 St. Paul Lez Durance Cedex, France 


\title{
Pressure tests supporting the qualification of the ITER EC H\&CD upper launcher diamond window
}

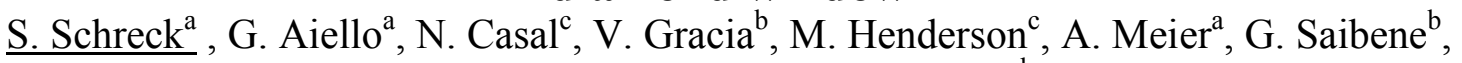
T. Scherer ${ }^{\mathrm{a}}$, D. Strauss ${ }^{\mathrm{a}}$, P. Wouters ${ }^{\mathrm{b}}$

${ }^{a}$ Karlsruhe Institute of Technology, Institute for Applied Materials, Association KIT-EURATOM, P.O. Box 3640, D-76021 Karlsruhe, Germany

${ }^{b}$ F4E Joint Undertaking, Josep Pla 2, 08019 Barcelona, Spain

${ }^{c}$ ITER Organization, Route de Vinon-sur-Verdon, CS 90 046, 13067 St. Paul Lez Durance Cedex, France

\begin{abstract}
The Electron Cyclotron diamond window which is located inside the port cell serves, together with an isolation valve, as primary vacuum boundary between the ITER vacuum vessel, the transmission lines and the port cell atmosphere and it functions as confinement barrier. The window consists of an ultra-low loss Chemical Vapor Deposition (CVD) diamond disk brazed into a metallic housing and it has to guarantee the compliance with very stringent nuclear safety requirements and an adequate transmission capability for high power mm-waves (1.31 MW at $170 \mathrm{GHz}$ ). The design of the window unit is approaching its final phase including design validation analyses, the development of a dedicated qualification program and prototyping activities.

In preparation of the testing of complete window prototypes, pressure tests were performed on a mock-up formed by a diamond disk $(\mathrm{D}=80 \mathrm{~mm}, \mathrm{~d}=1.11 \mathrm{~mm})$ brazed to two copper cuffs. The scope of the experiments was to show both the capability of the joining between the disk and the cuffs to keep the required vacuum tightness as well as the integrity of the disk when exposed to pressure loads. Based on the requirements defined for the pressure scenarios during normal operation and off-normal events, a test program was developed accounting for cyclic tests at low pressure differentials and overpressure tests up to 2 bar pressure difference over the disk to simulate severe accidental conditions.

This paper gives an outline of the ongoing development of the overall qualification program of the ITER torus window and reports specifically on the experimental set-up and the successful outcome of the pressure tests of the brazed diamond disk mock-up. The test program for the complete window prototype needs discussion and approval by F4E and ITER and will directly determine the final qualification program for the series diamond windows.
\end{abstract}

Keywords: ITER, Upper Launcher, Diamond, Window, Prototype

\section{Introduction}

The EC Upper Launcher system of ITER, which is a Nuclear Facility INB No. 174, is divided into two groups of components. There is the upper launcher assembly and the First Confinement System (FCS) (Fig. 1). The first includes the in-vessel components, i.e. the plug structure (except its back end), the blanket shield module (BSM), the in-vessel optical system with the mirrors and other internal components (e.g. shield blocks) and the FCS starts at the back end of the plug and goes through an ex-vessel waveguide system up to the isolation valve and the diamond window assembly (DWA). The four upper launchers (in ports 12, 13, 15, 16) have the main purpose to drive local current with the aim to control the plasma instabilities (mitigate NTMs) [1],[2],[3].

The isolation valve and the DWA form the barriers of the first confinement system for tritium and other hazardous materials contained in the Vacuum Vessel and serve as part of the primary vacuum boundary as well. Thus, the most stringent requirements for safety apply for the DWA, which is classified as protection important component (PIC) of safety important class 1 (SIC1).

The window assembly consists of an ultra low loss CVD diamond disk $\left(\tan \delta<2 \times 10^{-5}\right)$ mounted in a system of metallic parts (Fig. 2) and is designed to be compatible with the transmission of $\mathrm{mm}$-wave power of up to $1.5 \mathrm{MW}$ (1.31 MW at window location) at $170 \mathrm{GHz}$ coming from the gyrotrons.

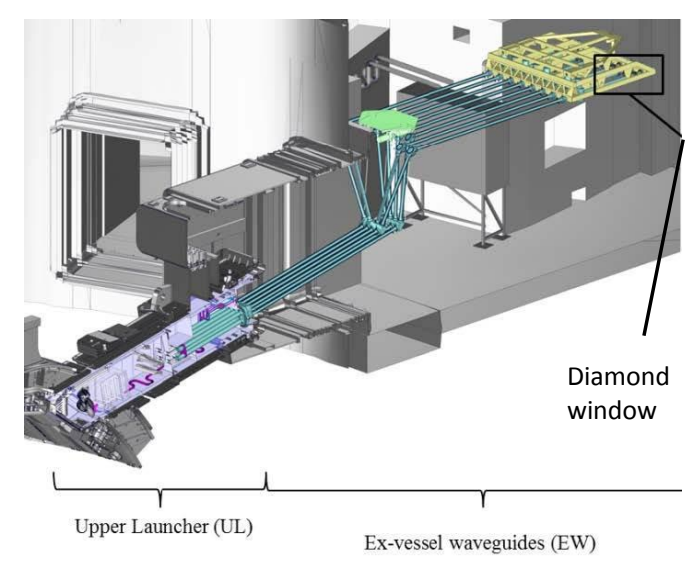

Fig. 1 Location of the diamond window assembly and the ex-vessel waveguides system of the upper launcher (UL).

As the diamond window cannot be completely covered by standard codes, a specific qualification program has to be developed, which also includes also prototyping activities. Already in the past, different prototypes of the window have been manufactured and tested. Design improvements have been taken place with respect to the $\mathrm{mm}$-wave transmission capability and the cooling efficiency (indirect cooling concept) [4], [5].

Within an ongoing contract with $\mathrm{F} 4 \mathrm{E}$, prototype work is continued. The complete window qualification and testing program is still under development and the tests will be executed with new prototype(s). The design 
of the window has been further developed taking into account the stringent safety requirements and new boundary conditions coming partly from changed external interfaces [6]. Next to the re-verification of the mm-wave transmission capability, it is necessary to proof the mechanical stability of the window against the expected loads. This includes pre-tests on window mockups with the aim to show evidence of the diamond disk stability against pressure loads.

\section{Prototype test and qualification program}

The test program for diamond window will consist of various tests, which are executed directly by the window manufacture or have to be performed by qualified labs. Particular tests are required for the bare disk, for the subassembly (disk already brazed to the copper cuff, which is welded to the cooling and cooling-diagnostic ring) and for the complete diamonds window assembly (Fig. 2).

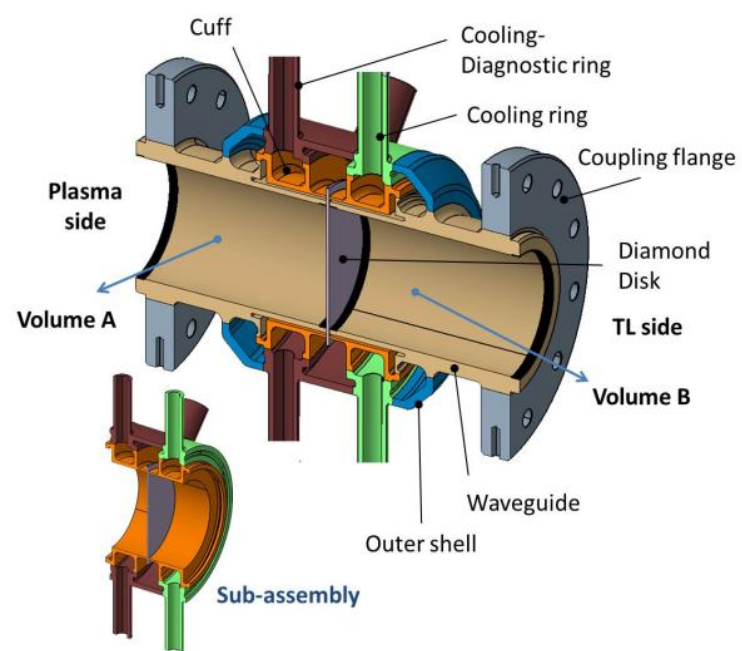

Fig. 2 Schematic diagram of the current window design. The inner waveguide diameter is $50 \mathrm{~mm}$ (after PCR-763). The main components are named. The picture in the bottom part shows the section view of the so called sub-assembly.

During the ongoing prototype work the test program for the bare disks has been developed and exercised successfully with diamond disks from Diamond Materials Freiburg [8]. The test programs for the window sub-assembly and the complete assembly are evolving.

Table 1 gives an overview of some main experiments/tests that are necessary for the window qualification. For all these measurements, acceptance criteria have been defined or will be defined in near future [8]. Additional experiments, e.g. inspections of the brazing seam between the disk and the copper cuff by X-ray tomography or deuterium permeation measurements for the complete assembly are considered at least at prototype stage. The final qualification program for the series production windows will be based on the experience gained during prototyping phase.

As for the manufacturing process also all tests have to be supplemented by an extensive documentation, including description of test procedures, data acquisition plans, calibration of the measurement setups, certifications of used materials, error analysis, etc.. All documentation needs to be agreed with F4E and ITER organization.

\begin{tabular}{|c|c|c|c|}
\hline & bare disk & sub-assembly & $\begin{array}{l}\text { complete } \\
\text { window }\end{array}$ \\
\hline $\begin{array}{l}\text { Geometrical } \\
\text { character- } \\
\text { risation }\end{array}$ & $\begin{array}{c}\text { diameter } \mathrm{D}, \\
\text { thickness } \mathrm{d} \\
\text { planarity, } \\
\text { roughness } \mathrm{R}_{\mathrm{a}}, \mathbf{M}\end{array}$ & $\begin{array}{l}\text { check of } \\
\text { tolerances } \\
\text { (drawings) } \\
\mathbf{M},(\mathbf{L})\end{array}$ & $\begin{array}{c}\text { check of } \\
\text { tolerances } \\
\text { (drawings) } \\
\mathbf{M},(\mathbf{L})\end{array}$ \\
\hline $\begin{array}{c}\text { Leak } \\
\text { tightness }\end{array}$ & n.a. & $\begin{array}{c}\text { Leakage rate } \\
\text { joint disk/cuff } \\
\mathbf{M},(\mathbf{L})\end{array}$ & $\begin{array}{c}\text { Leakage rate } \\
\text { joint disk/cuff, } \\
\text { all welded } \\
\text { joints, } \mathbf{M}\end{array}$ \\
\hline $\begin{array}{c}\text { Water flow, } \\
\text { water } \\
\text { pressure }\end{array}$ & n.a. & n.a. & $\begin{array}{l}\text { check of tight- } \\
\text { ness; cooling } \\
\text { efficiency } \\
\text { M, (L) }\end{array}$ \\
\hline $\begin{array}{c}\text { Dielectric } \\
\text { properties, } \\
\text { mm-wave } \\
\text { trans- } \\
\text { mission }\end{array}$ & $\begin{array}{l}\text { loss tangent: } \\
\text { central and } \\
\text { mapping (low } \\
\text { power, } \\
\text { Fabry-Perot } \\
\text { resonators), L }\end{array}$ & $\begin{array}{c}\text { loss tangent: } \\
\text { central } \\
\text { (low power, } \\
\text { Fabry-Perot } \\
\text { resonator), } \\
\mathbf{L} \\
\end{array}$ & $\begin{array}{c}\text { For prototype: } \\
\text { High power } \\
\text { mm-wave } \\
\text { transmission } \\
\text { experiments, } \\
\mathbf{L} \\
\end{array}$ \\
\hline
\end{tabular}

Table 1: Tests at the different stages of the window manufacturing (M: tests at manufacturer site, L: tests at specific labs, e.g. KIT-IAM for the dielectric loss characterisation [7], [8] for some tests responsibilities are still under discussion).

Apart from the list above, tests are necessary to support the validation of the design with respect to mechanical stability, especially to prove the stability of the diamond disk against pressure loads. Fracture tests using a ring-on-ring set-up have been recently conducted on five disks of the relevant thickness $(\mathrm{d}=1.11 \mathrm{~mm})$, but with a smaller diameter $(\mathrm{D}=30 \mathrm{~mm})$. The growth side of the diamond disks has been under tensile stress. The determined flexural strength values have differed between 295-333 MPa (314 MPa on average) [9]. The boundary conditions of these ring-on-ring tests are not completely comparable to the real conditions (disk geometry and its integration in the window assembly). Therefore and for lack of a complete prototype, pressure tests were performed using a mock-up made of a typical high quality diamond disk brazed to a copper cuff.

\section{Pressure test window mock-up}

\subsection{Requirements and test set-up}

Following an ITER Requirement Note on the pressure cycles for torus diamond window (RN-52UL-017, short $\mathrm{RN}-17$ ) different pressure gradients over the disks are expected to be seen by the diamond disk for various events during the window lifetime [11]. The relevant pressure loading conditions to be considered for the window qualification, coming from leak test and maintenance operations as well as from accidental events (Cat I-IV) are summarized in Table 2. The 2.0 bar torus pressure event (Code No.12; Cat IV) is the worst event considered, and it corresponds to a multiple in vessel pipe failure. It is worth reminding that, for this already extremely unlikely (Cat IV) event to happen at the window, the additional failure of the $\mathrm{EC}$ isolation valve to close must occur.

With the scope to simulate the listed pressure conditions, pressure tests were performed with a window mock-up, which consists of a bare diamond disk brazed to a simplified copper cuff. The dimension of the disk $(\mathrm{D}=80 \mathrm{~mm}, \mathrm{~d}=1.11 \mathrm{~mm})$ is compliant with the original/pre-PCR-763 window design with an inner WG diameter of $63.5 \mathrm{~mm}$. The mock-up was manufactured 
by Diamond Materials GmbH (Freiburg) and mimics the fixed restraint of the disk in the later complete window as best as possible.

\begin{tabular}{|l|l|c|c|c|}
\hline $\begin{array}{l}\text { ID } \\
\text { Test }\end{array}$ & $\begin{array}{l}\text { Codes } \\
\text { from } \\
\text { RN 17 }\end{array}$ & $\begin{array}{l}\text { Pressure } \\
\text { gradient }\end{array}$ & $\begin{array}{l}\text { Number of } \\
\text { cycles } \\
\text { expected } \\
\text { for lifetime }\end{array}$ & $\begin{array}{c}\text { Number } \\
\text { of cycles } \\
\text { applied in } \\
\text { the tests }\end{array}$ \\
\hline A & 1 & $+0.12 \mathrm{bar}$ & 610 & 1700 \\
\hline $\mathbf{X}$ & $2+6$ & $+10^{-3} \mathrm{bar}$ & $3.5 \cdot 10^{3}$ & negligible \\
\hline $\mathbf{A}^{*}$ & $\begin{array}{l}4 \mathrm{a}+5 \mathrm{a}+7 \\
+11 \mathrm{a}\end{array}$ & $+0.1 \mathrm{bar}$ & 65 & $\begin{array}{c}\text { test within } \\
\text { ID A }\end{array}$ \\
\hline B & $4 \mathrm{~b}+5 \mathrm{~b}$ & $-0.1 \mathrm{bar}$ & 48 & 120 \\
\hline C & 8 & $+1.0 \mathrm{bar}$ & 1 & 21 \\
\hline D & 10 & $-1.0 \mathrm{bar}$ & 2 & 23 \\
\hline E & 12 & +2.0 bar & 1 & 1 \\
\hline $\begin{array}{l}\text { Definition in RN 17: A positive pressure gradient corresponds to a } \\
\text { higher pressure on the torus / plasma side of the window disk, while } \\
\text { a negative gradient has a higher pressure on the TL / gyrotron side. }\end{array}$ \\
\hline
\end{tabular}

Table 2: List of pressure gradients and expected number of cycles seen by a diamond window disk. (Allowable leak rate $\leq 1 \cdot 10-9 \mathrm{mbar} \cdot 1 / \mathrm{s}$.) (defined in VHB)

An automatic computer controlled vacuum system with several valves allows the realization of reproducible pressure cycles. The principle set-up is shown in Fig. 3. The mock-up (1) is connected on both sides vacuum tight to the system. The lower part is evacuated to a pressure level $\mathrm{p}_{\mathrm{vac}}<10^{-5}$ mbar by the high vacuum pump HP3. The pre-pump for the expansion to atmosphere is VP3 and monitoring is realized by the vacuum gauge P005. The upper side of the mock-up can be loaded by pressure of nitrogen gas (3) or by vacuum (P001) applied by using a spiro-booster pump (VP2) and passing the valve V4. By operating valves V5 and V6, all states between atmospheric pressure and defined vacuum conditions according to Table 2 can be obtained. The respective switching operations of the valves are actuated by a computer program to which trigger points are given as input parameters.

The proper functionality of the system was checked with a dummy without a diamond disk. The scope of these pre-experiments was to find the optimum cycles of operations and the pre-settings (adequate trigger points, ranges for durations for pressure rise and decline,...).

The orientation of the diamond disk plays an important role. It is known that the fracture toughness of a diamond disk produced by the CVD process is dependent from its orientation, i.e. if the growth or the nucleation side of the disk is under tensile stress. The mechanically more unstable side is the growth side of the disk [10]. The diamond disk inside the installed ITER window will be therefore oriented with the growth side toward the plasma to get the favorable configuration for the torus over pressure case.

Also in the setup for the mock-up testing there are two possibilities for the installation. If the growth side of the diamond disk is directed to the variable pressure (GS up), this corresponds to a positive pressure gradient over the disk. Nucleation side up respectively means a negative pressure gradient. The mock-up ID (P-T05DM-DM) is laser marked on the side of the cuff that is connected to the GS. As a consequence, this always allows a control of the correct installation to the system.

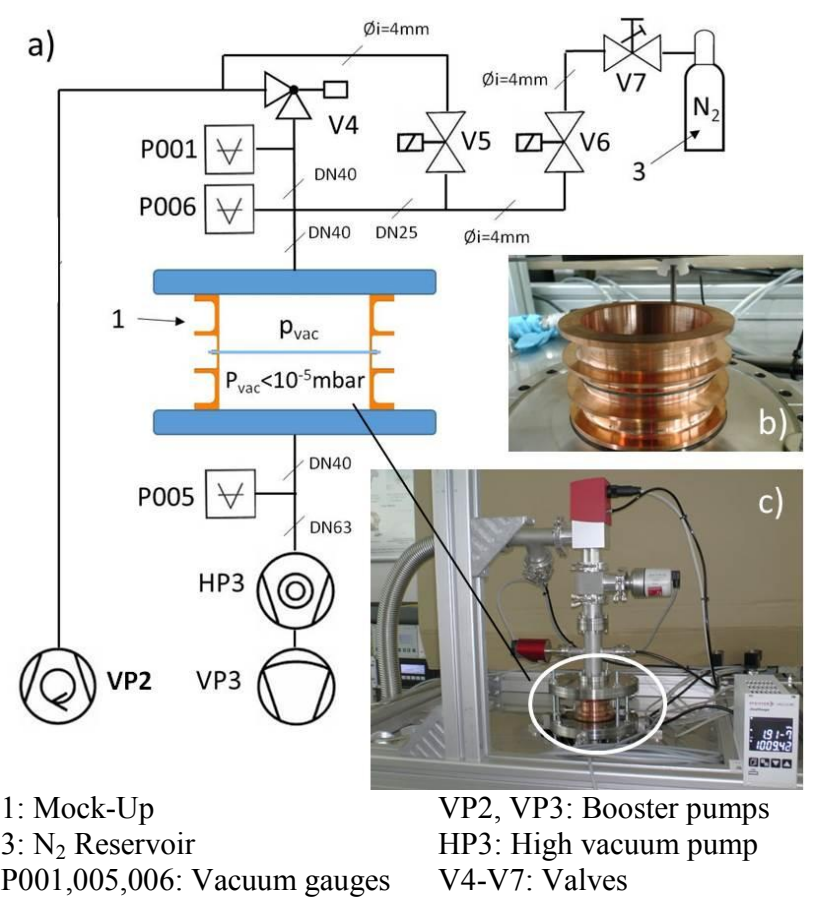

Fig. 3 Experimental setup for cyclic pressure tests:

a) Principle sketch, b) pre-installed mock-up (lower side connected to the HP3/VP3 system, which provides the vacuum $\left.\left(<10^{-5} \mathrm{mbar}\right), \mathrm{c}\right)$ photo of the set-up with installed dummy.

\subsection{Cyclic tests}

Tests A, B, C and D from Table 2 are considered as cyclic pressure tests and were performed using the automated set-up. In order to have some margin, the real number of cycles for the experiments (last column) are higher than the numbers of expected cycles during window lifetime (factor 2-3 or even higher).

In Fig. 5 an excerpt from a pressure cycle experiments is given, showing a typical pressure variation over time. The graph is originated from the pre-test for 100 mbar. For all real tests the maximum level of the pressure (level 3, monitored by P006) was always set to the respective pressure gradient plus $10 \%$.

For example in case of Test B, being the first test that was performed, NS was orientated upwards and the level 3 trigger point was set to 110 mbar.

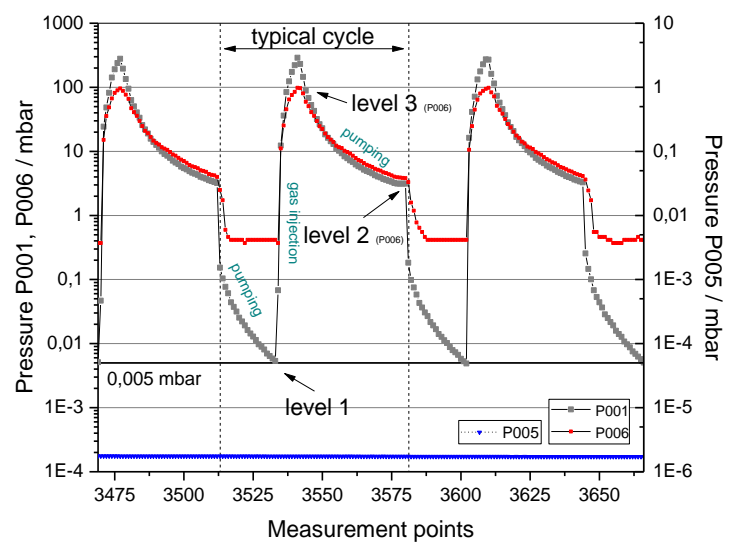

Fig. 4 Pre-measurement for test B, showing some typical cycles (Measurement points: 2/sec, switch point level 1 to start gas injection: $5^{*} 10^{-3}$ bar, trigger point for level 3: 100mbar). 
After every test round, the leak tightness was measured for both sides of the mock-up using the hard vacuum test method in which the part is connected to the detectors analyzer cell and tracer gas (He) is sprayed on the points that are likely to leak. In advance to the measurements, the leak tester (Pfeiffer ASM 340) was calibrated using an external calibrated leak. The measured leak rate after each test was always smaller than the requested $1 \cdot 10^{-9} \mathrm{mbar} \bullet 1 / \mathrm{s}$. This implies that the mock-up was fully intact after all cyclic tests, i.e. neither the disk nor the brazing was corrupted by the cyclic pressure loads.

\subsection{High pressure test}

The mechanical stability of the disk against overpressure was finally checked by a test in which the pressure was increased manually up to 2 bar (test $\mathrm{E}$ in Table 2). The set-up in Fig. 3 was slightly modified. No automation was used, V4, V5 and VP 2 were disconnected and vacuum gauges $\mathrm{P} 001$ and $\mathrm{P} 006$ were substituted by a P006* pressure sensor (PTI-S-MG.06-15AT). The mock-up was connected with the NS downwards (under vacuum), GS was orientated up and pressure was applied to simulate the 2 bar overpressure of the torus.

The respective diagram for the stepwise pressure increase (steps $\sim 0.1$ bar by opening and closing manually V6) is shown in Fig. 5. In addition to the displayed experiment with a slow rise to 2 bar, also a test with a direct pressure increase up to 2 bar (quick rise, V6 automatically opened) and a test with atmospheric pressure on NS and 3 bar pressure on GS (slow rise) were performed. In all cases, the maximum pressure was increased up to the 2 bar ( 3 bar) plus a safety margin, taking into account measurement uncertainties. Finally, every experiment was completed with the measurement of the leak rate, which was found to be below the requested limit, even after the $3^{\text {rd }}$ variant of the high pressure experiment with the pressure gradient of 2 bar.

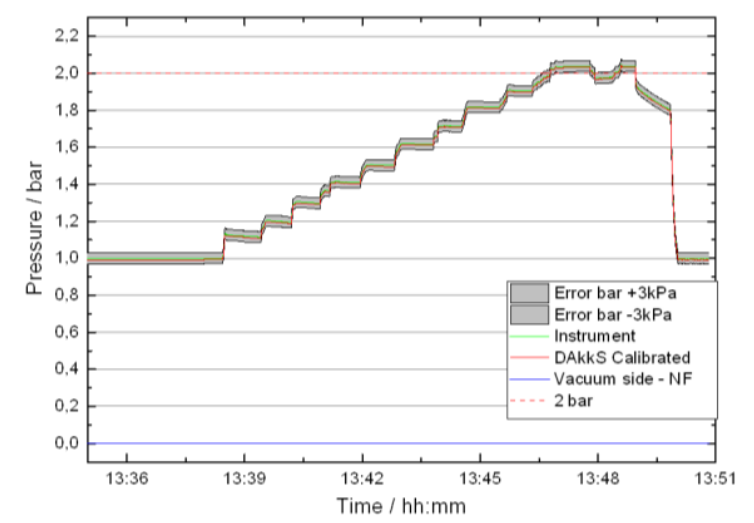

Fig. 5 Pressure increase during 2 bar test (stepwise).

\section{Conclusions and Outlook}

The successful pressure tests (cyclic and 2 bar) performed with the window mock-up have shown the capability of the system of disk-cuff to withstand the expected pressure loads. The experiments are supporting the window qualification and help to verify the window design with respect to the mechanical integrity of the disk connected to the copper cuff. Especially the fact that the disk survived three times the extremely unlikely event of 2 bar overpressure gives additional confidence for the adequacy of the disk thickness of $1.11 \mathrm{~mm}$. Furthermore, it needs to remind that the open aperture in the mock-up is $63.5 \mathrm{~mm}$, while the new window design shall have a reduced aperture of $50 \mathrm{~mm}$. Thus, the performed experiments can be rated as conservative since, going to the $50 \mathrm{~mm}$ aperture, the system becomes stiffer.

Nevertheless it is recommended to perform similar (prototype)-experiments with the diamond disk integrated into the complete window assembly.

Next steps of work shall be to demonstrate the feasibility of the window manufacturing and the performance of further tests with the future prototype(s) allowing a validation of the window design and the later qualification of the windows in series production.

\section{Acknowledgments}

This work is/was supported by Fusion for Energy (F4E) (contracts No. OPE-467). The views and opinions expressed herein reflect only the author's views and not necessarily those of F4E and ITER Organisation. F4E and IO are not liable for any use that may be made of the information contained therein.

\section{References}

[1] F. Albajar et al., Status of Europe's contribution to the ITER EC system, EPJ Web of Conferences 87, 04004, (2015)

[2] D. Strauss et al., Progress of the ECRH Upper Launcher design for ITER, Fusion Eng. Des., 89 (2014) 1669-1673.

[3] T. OMORI et al., Overview of the ITER EC H\&CD System and Its Capabilities, Fusion Eng. Des. 86 (2011) 951.

[4] T. A. Scherer et al., Experimental analysis of the inserted waveguide CVD diamond window Infrared, Millimeter and Terahertz Waves (IRMMW-THz), 2011.

[5] S. Schreck et al., ITER ECRH Upper Launcher: Test plan for qualification of the Diamond Torus Window Proto-type III, Fusion Eng. Des. 109-111 (2016) 1232-1236.

[6] G. Aiello et al., The ITER EC H\&CD upper launcher: methodology in the FEM analyses of the diamond window unit subject to seismic and baking loads, 2015 IEEE 26th Symposium on Fusion Engineering (SOFE).

[7] F. Königer, Measurement system for the precise determination of dielectrical properties in the mm-wave range based on hemispherical open resonators. Frequenz 43 (1989).

[8] S. Schreck, et al., ITER ECRH upper launcher torus diamond window - Prototyping, testing and qualification, Fusion Eng. Des. (2015), Vol. 96-97, 593-596.

[9] S. Schreck et al.; ITER ECRH Upper Launcher diamond window - Qualification and testing of a Protection Important Component, in press https://doi.org/10.1016/j.fusengdes.2018.02.100.

[10] R. Spörl, Einfluss des Gefüges auf mechanische Festigkeit und dielekt. Eigenschaften von CVD Diamant, Forschungszentrum Karlsruhe GmbH, Editor., 2001

[11] N. Casal; RN-52UL-017 Window pressure cycles v1.9 (2017); internal communication. 